\title{
Pemanas Kue Pukis Otomatis Berbasis Mikrokontroler
}

\author{
Ali Basrah Pulungan ${ }^{1}$, Hamdani², Hastuti ${ }^{3}$, dan Arzi Afriyanda ${ }^{4}$ \\ 1,2,3,4 Universitas Negeri Padang \\ Jl. Prof Dr. Hamka Air Tawar, Padang, Indonesia \\ alibp@ft.unp.ac.id ${ }^{1}, \underline{\text { hamdani@ft.unp.ac.id }}^{2}$, hastuti@ft.unp.ac.id $^{3}$
}

\begin{abstract}
The development of modern technologies and automation of electronic devices today makes work easier. For example in the temperature control system on a heater that is designed more automatically, in the manufacture of this Pukis cake heater, it is supported by supporting components such as atmega 32 microconroler as a control center for pukis cake heaters, thermocouple sensors as temperature detectors, heater as heating element, fan as regulator of air circulation on the heater, the keypad functions as a medium input temperature setting on the heater, LCD as a display media output on the heater, and the Buzzer as an alarm on the baking cake heater. In the design of the baking pan, the tool can work well and in accordance with what the author plans.
\end{abstract}

Keywords - atmega 32 microcontroller, thermocouple sensor, heater, fan, keypad, lcd, buzzer.

\begin{abstract}
Abstrak- Perkembangan teknologi modern dan otomatisasi perangkat elektronik saat ini membuat pekerjaan menjadi lebih mudah. Misalnya dalam sistem kontrol suhu pada pemanas yang dirancang lebih otomatis, dalam pembuatan kue pemanas Pukis ini, didukung oleh komponen pendukung seperti mikrokontroler ATMega 32 sebagai pusat kontrol untuk pemanas kue pukis, sensor termokopel sebagai detektor suhu , pemanas sebagai elemen pemanas, kipas sebagai pengatur sirkulasi udara pada pemanas, keypad berfungsi sebagai pengaturan suhu input medium pada pemanas, LCD sebagai media tampilan keluaran pada pemanas, dan Buzzer sebagai alarm pada pemanas kue kue . Dalam desain loyang, alat tersebut dapat bekerja dengan baik dan sesuai dengan apa yang penulis rencanakan.
\end{abstract}

Kata kunci- mikrokontroler ATMega 32, thermocouple sensor, heater, fan, keypad, lcd, buzzer.

\section{Pendahuluan}

Kemajuan teknologi pada saat sekarang sudah sangat maju, semua pekerja dapat dilakukan dengan cara otomatis yang bertujuan untuk memudahkan pekerjaan manusia. Perkembangan teknologi yang semakin pesat telah merambah dunia kuliner, seperti alat pemanas kue otomatis. Hal ini didukung adanya perangkat digital berbasis mikrokontroler sehingga data kendali dapat disimpan dalam memori yang sewaktu-waktu dapat dipanggil kembali [1].

Pada saat sekarang ini sudah banyak bermunculan usaha pengolahan kue, seperti pedagang kue pukis yang banyak ditemukan di pasar-pasar tradisional bahkan di tepi-tepi jalan. Akan tetapi usaha tersebut masih jauh dari kesempurnaan dikarenakan kurangnya alat pendukung seperti belum adanya alat pemanas kue pukis. Kemajuan tekhnologi khususnya dibidang kontrol memungkinkan proses pengendalian suhu dilakukan secara elektronik yang dapat digunakan sebagai pemanas kue pukis.

Alat pemanas kue pukis yang dirancang dapat bekerja dengan rentang suhu sampai $40^{\circ} \mathrm{C}$ dilengkapi dengan komponen-komponen seperti mikrokonroler atmega 32 sebagai pusat kendali, sensor thermocouple, heater, fan dan keypad serta LCD sebagai media output tampilan suhu pada alat pemanas.

\section{Mikrokontroler ATMega 32}

Mikrokontroller sebagian besar elemenya dikemas dalam satu chip IC (intergrated Circuit) disebut sebagai single chip microcomputer. Ini merupakan sebuah sistem komputer yang termasuk dalam kategori embedded komputer [2][3]. Salah satu jenisnya adalah mikrokontroler AVR (Alf and Vegard's Risc processor).

Mikrokontroler AVR menggunakan arsitektur RISC (Reduce Instruction Set Computing) yang mempunyai lebar bus data 8 bit. Perbedaan ini bisa dilihat dari frekuensi kerjanya. MCS51 memiliki frekuensi kerja seperduabelas kali frekuensi osilator sedangkan frekuensi kerja AVR sama dengan frekuensi osilator. Jadi dengan frekuensi osilator yang sama, kecepatan AVR dua belas kali lebih cepat dibanding kecepatan MCS51 [4].

Mikrokontroler ATMega 32 merupakan komponen elektronika yang isinya rangkaian elektronik yang berisi chip ATMega 32. Pada perancangan alat ini, berfungsi untuk mengontrol pemanas kue pukis.

Secara umum konfigurasi dan fungsi pin ATMega 32 dapat dijelaskan sebagai berikut:

1. VCC merupakan pin yang berfungsi sebagai masukan catu daya.

2. GND merukan pin Ground.

3. Port A (PortA0...PortA7) berfungsi sebagai input analog dari ADC (Analog to Digital Converter). Port ini 
juga berfungsi sebagai port I/O dua arah, jika ADC tidak digunakan.

4. Port B (PortB0...PortB7) berfungsi sebagai port I/O dua arah. Port B5, PB6 dan PB7 juga berfungsi sebagai MOSI, MISO dan SCK yang dipergunakan pada proses downloading.

\begin{tabular}{|c|c|c|c|c|c|c|c|}
\hline & & & & & & & \\
\hline$(\mathrm{XCK} / \mathrm{TO})$ & PBO & 마 & 1 & 40 & $\sqsubseteq$ & PAO & $(A D C O)$ \\
\hline (T1) & PB1 & 마 & 2 & 39 & $巨$ & PA1 & (ADC1) \\
\hline (INT2/AINO) & PB2 & 미 & 3 & 38 & $\sqsubseteq$ & PA2 & (ADC2) \\
\hline (OCO/AIN1) & PB3 & 마 & 4 & 37 & $\sqsubseteq$ & PA3 & (ADC3) \\
\hline$(\overline{\mathrm{SS}})$ & PB4 & 마 & 5 & 36 & $\sqsubseteq$ & PA4 & (ADC4) \\
\hline (MOSI) & PB5 & 미 & 6 & 35 & $\sqsubseteq$ & PA5 & (ADC5) \\
\hline (MISO) & PB6 & 마 & 7 & 34 & $\sqsubseteq$ & PA6 & (ADC6) \\
\hline (SCK) & PB7 & 마 & 8 & 33 & $\sqsubseteq$ & PA7 & (ADC7) \\
\hline & ESET & 마 & 9 & 32 & 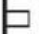 & AREF & \\
\hline & VCC & 미 & 10 & 31 & $巨$ & GND & \\
\hline & GND & 마 & 11 & 30 & 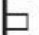 & AVCC & \\
\hline & TAL2 & 무 & 12 & 29 & $巨$ & $\mathrm{PC} 7$ & (TOSC2) \\
\hline & TAL1 & $\square$ & 13 & 28 & 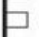 & PC6 & (TOSC1) \\
\hline$(R \times D)$ & PDO & $\square$ & 14 & 27 & $\sqsubseteq$ & $\mathrm{PC5}$ & \\
\hline$(T \times D)$ & PD1 & 口 & 15 & 26 & 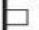 & $\mathrm{PC}_{4}$ & \\
\hline (INTO) & PD2 & $\square$ & 16 & 25 & $\sqsubseteq$ & PC3 & \\
\hline (INT1) & PD3 & 무 & 17 & 24 & 巨 & $\mathrm{PC} 2$ & \\
\hline (OC1B) & PD4 & 무 & 18 & 23 & 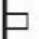 & $\mathrm{PC} 1$ & (SDA) \\
\hline (OC1A) & PD5 & 무 & 19 & 22 & $巨$ & PCO & (SCL) \\
\hline (ICP1) & PD6 & 무 & 20 & 21 & $\sqsubseteq$ & PD7 & $(\mathrm{OC2})$ \\
\hline
\end{tabular}

Gambar 1.Pemetaan Pin Atmega 32 [5]

\section{Sensor Thermocouple}

Termokopel (thermocouple) merupakan dua buah kawat logam yang ujungnya saling menyatu. Salah satu ujung dari termokopel yang disatukan disebut hot junction, bagian ini yang terhubung pada objek yang diukur suhunya dan ujung yang lain disebut cold junction.

Termokopel pada alat pemanas kue pukis berfungsi sebagai pendeteksi suhu pada saat proses pemanasan kue, termokopel terhubung pada port B yang terdapat pada mikrokontroler ATMega 32. Konstruksi termokopel diperlihatkan pada gambar:

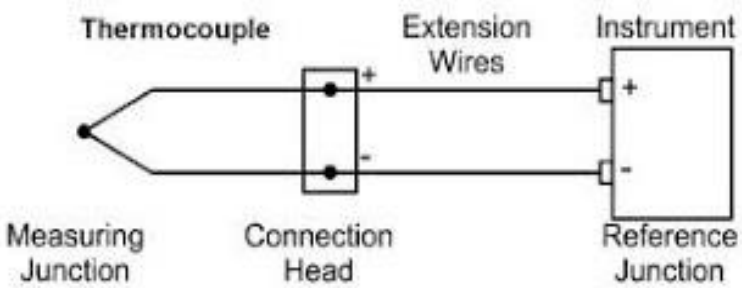

Gambar 2. Termokopel

\section{Heater}

Heater adalah sebuah alat yang biasanya terbuat dari logam berupa lempengan, silinder pejal maupun berupa kawat pejal dibentuk menjadi spiral. Heater terhubung dengan mikrokontroler ATMega 32 pada bagian port B. Bentuk dan tipe dari elemen pemanas listrik ini akan disesuaikan dengan kebutuhan alat sehingga elemen heater dapat bekerja dengan baik.
Spesifikasi heater yang digunakan:

Jenis heater : Finned Heater U Form

Tegangan : $220 \mathrm{VAC}$

Frekuensi $: 50 / 60 \mathrm{~Hz}$

Daya : 300 Watt

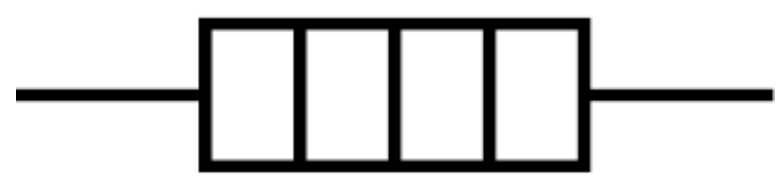

Gambar 3. Heater

Fan

Fan DC berfungsi sebagai pengatur sirkulasi udara di dalam alat pemanas, sehingga sirkulasi udara pada alat pemanas stabil dan merata. Fan ini bekerja pada tegangan $12 \mathrm{VDC}$.

Spesifikasi Fan Dc :

$\begin{array}{ll}\text { Tegangan } & : 12 \mathrm{VDC} \\ \text { Konsumsi daya } & : 4 \mathrm{Watt} \\ \text { Diameter } & : 8 \mathrm{Cm}\end{array}$

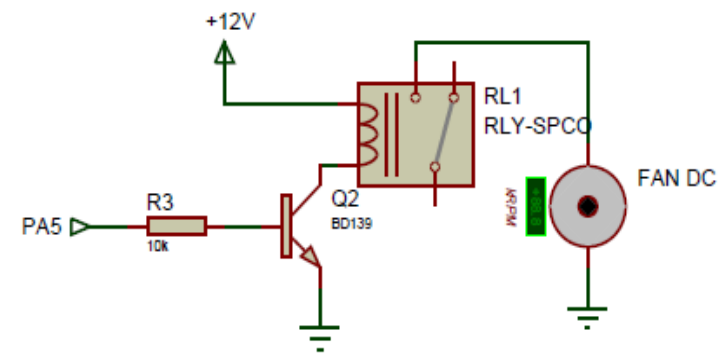

Gambar 4. Rangkaian Fan dc

\section{Komponen lainnya}

Berikut komponen beberapa komponen lainnya yang digunakan pada alat pemanas kue pukis :

1. Keypad berfungsi sebagai media untuk menginput data pada alat pemanas kue pukis. Keypad ini terhubung pada mikrokontroler di bagian port A.

2. LCD (Liquid Crystal Display) sebagai tampilan data Pada pemanas kue pukis ini LCD berfungsi sebagai monitoring suhu dan terhubung di mikrokontroler ATMega32 pada bagian port $C$.

3. Buzzer pada alat pemanas kue pukis bekerja sebagai alarm, apabila proses pemanasan sudah selesai. Buzzer terhubung pada mikokontroler ATMega32 di bagian Port B. 


\section{METODE PENELITIAN}

Pada perencanaan alat ini metode perancangan alat terdiri dari blok diagram, rancangan mekanik dan flowchart yang saling berkaitan.

\section{Blok Diagram}

Prinsip kerja alat pemanas kue pukis ini bekerja dengan menggunakan catu daya. dimana catu daya ini berfungsi menurukan tegangan dari sumber PLN 220V menjadi tegangan $5 \mathrm{~V}$ dan $12 \mathrm{~V}$, mikrokontroler bekerja pada tegangan $5 \mathrm{~V}$ langsung terhubung dengan Termokopel, LCD, Buzzer, dan Keypad. Semua komponen ini saling terhubung dengan mikrokontroler, dimana mikrokontroler sebagai pusat kendali alat. Sedangkan fan DC pada alat pemanas kue pukis bekerja dengan tegangan $12 \mathrm{~V}$ dimana fan DC berfungsi sebagai mengatur sirkulasi udara pada alat pemanas kue pukis. Sehingga pemanas yang dihasilkan merata keseluruh ruangan. Sedangkan komponen untuk memanaskan kue pukis penulis menggunakan heater, dimana heater bekerja pada tegangan 220V. Untuk mengatur suhu pada pemanas kue pukis penulis menggunakan termokopel.

Langkah pertama untuk merencanakan pembuatan alat pemenas kue pukis, yaitu dengan cara membuat blok diagram, dimana blok diagram ini bertujuan unntuk merancang sistem alat pemanas kue pukis yang tentu nya saling berkaitan berikut blok diagram alat pemanas kue pukis.

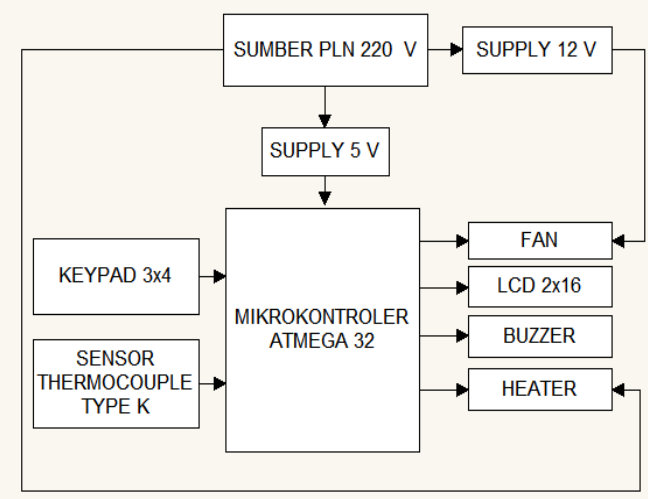

Gambar 6. Blok Diagram Sistem.

\section{Perancangan Alat}

Perancangan alat disini merupakan sebuah kotak alat pemanas kue pukis dengan ukuran $500 \mathrm{~mm} \times 350 \mathrm{~mm} \times$ $500 \mathrm{~mm}$. Ukuran tersebut menyesuaikan dengan komponen-komponen yang ada dan menyesuaikan dengan jumlah kue pukis yang akan dipanaskan.

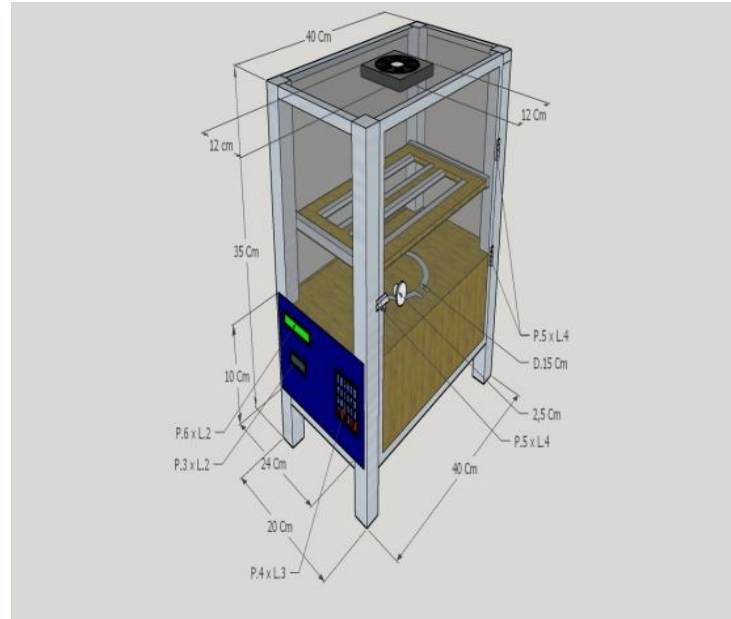

Gambar 7. Rancangan Fisik Alat.

\section{Flowchart}

Flowchart merupakan diagram alir dalam perancangan program yang akan dibuat sesuai perinsip kerja alat yang akan dihasilkan. Berikut rancangan flowchart alat pemanas kue pukis.

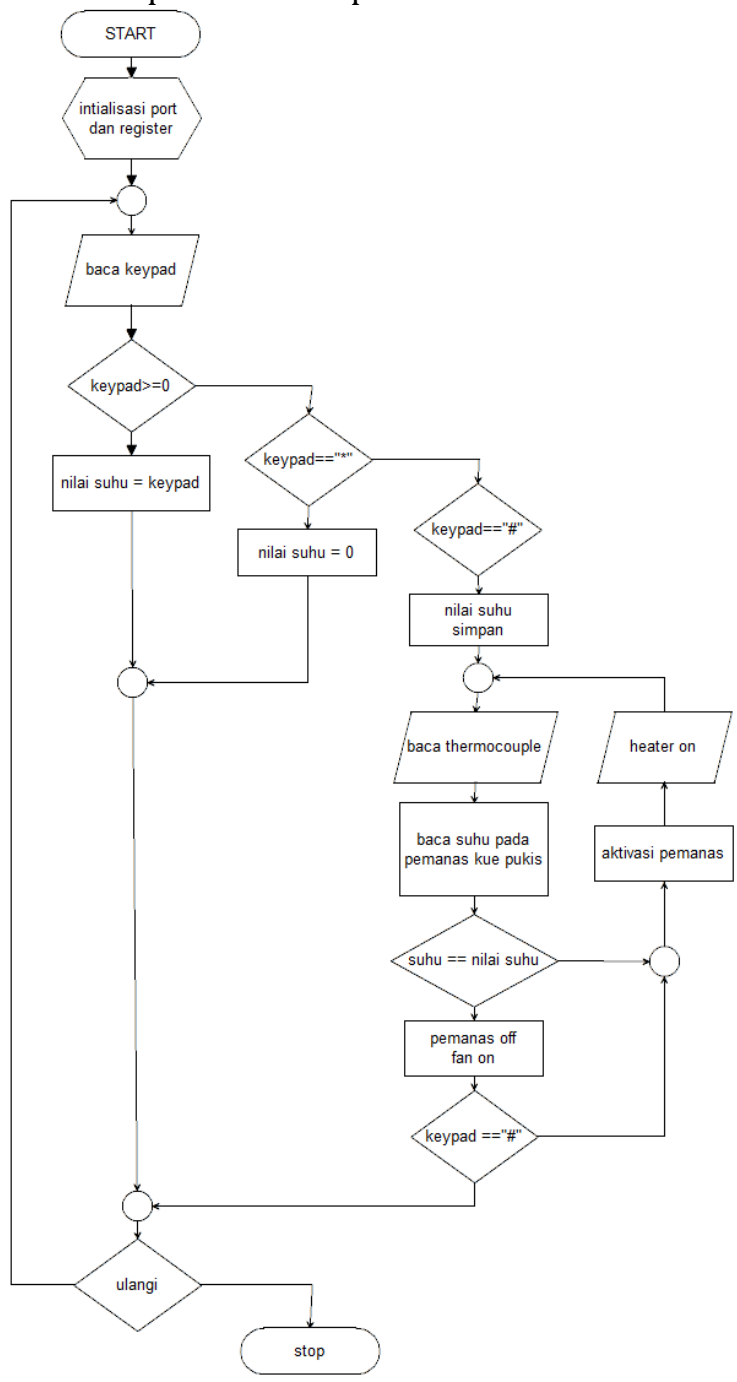

Gambar 8. Flowchart 


\section{HASIL DAN PEMBAHASAN}

Pada bagian akan dijelaskan cara pengujian alat pemanas kue pukis. Pengujian dilakukan untuk mendapatkan data-data yang digunakan untuk analisis sehingga dapat diambil kesimpulan tentang kinerja alat yang dibuat.

\section{Pengujian Alat Pemenas Kue Pukis Secara Keseluruhan}

Pengujian alat secara keseluruhan bertujuan untuk mengetahui hasil ideal alat dapat bekerja baik atau tidak. dalam melakukan pengujian penulis melakukan pengujian pada bagian bagian komponen yang terdapat pada pemanas kue pukis.

1. Pengujian Minimum Sistem ATMega 32

Pengujian rangkaian sistim minimum mikrokontroler Atmega32 diukur dengan menghubngkan rangkaian catu daya 5Vdc. Pengukuran tegangan dilakukan terhadap parameter logika '0' dan logika '1' pada port I/O mikrokontroller ATmega 32. Mikrokontroler ATMega32 memiliki tegangan kerja antara 4.5 Vdc - 5,5 Vdc dan bekerja pada dua kondisi logika yaitu kondisi low (0), dimana tegangan yang terbaca pada instrument pengukuran tegangan port sebesar 0 VDC berarti sistem ini masih dalam batas ideal. Logika yang kedua yaitu dalam kondisi high (1) dimana tegangan yang terbaca pada instrumen pengukuran tegangan didapat tegangan port sebesar 4,9 Vyang berarti sistem masih dalam batas ideal.

\section{Pengujian Sensor Thermocouple}

Rangkaian sensor diuji dengan cara mengukur tegangan keluaran dari rangkaian sensor Thermocouple. Pengukuran dilakukan dengan memberikan tegangan supply pada rangkaian sensor sebesar 5 Vdc. Pada pengujian rangkaian sensor dilakukan pengukuran perubahan suhu yang terjadi akibat adanya pemanas yang aktif sebagai pemanas kue pukis. Hasil pengujian sensor diperlihatkan pada tabel 1.

\section{Pengujian Heater}

Dalam rangkaian ini menggunakan Heater yang berfungsi untuk memanaskan kue pukis dari pengentrian yang dilakukan. Hasil yang di dapat dari pengukuran heater, heater bekerja dalam kondisi aktif memerlukan tegangan 220V. Dan dalam keadaan tidak aktif tegangan yang terbaca $0 \mathrm{~V}$.

\section{Pengujian Fan Driver}

Pengujian rangkaian driver fan dilakukan untuk mengetahui apakah rangkaian driver fan ini bisa bekerja dengan semestinya.Pengujian dilakukan dengan memberikan logika 1 (satu) dan 0 (nol). Hasil pengukuran fan dalam keadaan aktif memerlukan tegana $12 \mathrm{~V}$, dan pada keadaan tidak aktif teganagn yang terukur $0 \mathrm{~V}$.

\section{Catu daya}

Pengukuran catu daya dilakukan dengan menggunakan alat ukur multimeter dengan keluaran yang dibutuhkan $5 \mathrm{~V}$ dan $12 \mathrm{~V}$. Hasil pengujian yang terukur pada catu daya pada titik pengukuran pertama yang terukur yaitu 11,9V DC, dan pada pengukuran titik kedua yaitu 4,9 V DC.

Tabel 1. Hasil Pengukuran Sensor Thermocouple

\begin{tabular}{|c|c|c|c|c|c|c|c|}
\hline \multirow{3}{*}{$\begin{array}{l}\text { Waktu } \\
\text { (menit } \\
\text { detik) }\end{array}$} & \multirow{2}{*}{$\begin{array}{l}\text { Pembacaan } \\
\text { Thermocopel }\end{array}$} & \multicolumn{6}{|c|}{ Pengujian Alat Ukur } \\
\hline & & $\begin{array}{c}\text { Posisi } \\
1\end{array}$ & $\begin{array}{c}\text { Posisi } \\
2\end{array}$ & $\begin{array}{c}\text { Posisi } \\
3\end{array}$ & $\begin{array}{c}\text { Posisi } \\
4\end{array}$ & $\begin{array}{c}\text { Posisi } \\
5\end{array}$ & $\begin{array}{c}\text { Posisi } \\
6\end{array}$ \\
\hline & $\left(\mathrm{C}^{3}\right)$ & $\left(\mathrm{C}^{3}\right)$ & $\left(\mathrm{C}^{3}\right)$ & $\left(\mathrm{C}^{3}\right)$ & $\left(\mathrm{C}^{3}\right)$ & $\left(\mathrm{C}^{3}\right)$ & $\left(\mathrm{C}^{3}\right)$ \\
\hline 0 & 25 & 26.30 & 26,35 & 26,39 & 26,31 & 26,37 & 26,39 \\
\hline 4 & 30 & 30,02 & 30,06 & 30,11 & 30,04 & 30,06 & 30,09 \\
\hline 5 & 31 & 30,05 & 30,08 & 30,13 & 30,06 & 30,10 & 30,13 \\
\hline 5,28 & 32 & 30,11 & 30,16 & 30,20 & 30,13 & 30.18 & 30,20 \\
\hline 5,47 & 33 & 31,70 & 31,73 & 31,76 & 31,71 & 31,72 & 31,75 \\
\hline 6,17 & 34 & 32,60 & 32,65 & 32,67 & 32,63 & 32,65 & 32,68 \\
\hline 6,55 & 36 & 33,90 & 33,94 & 33,99 & 33,95 & 33,94 & 33,96 \\
\hline 7,21 & 37 & 35,40 & 35,45 & 35,49 & 35,42 & 35,47 & 35,49 \\
\hline 7,41 & 38 & 36,20 & 36,24 & 36,26 & 36,22 & 36,26 & 36,28 \\
\hline 7,52 & 39 & 36,70 & 36,72 & 36,75 & 37,73 & 36,73 & 36,75 \\
\hline 8,03 & 40 & 37,70 & 37,71 & 37,75 & 37,71 & 37,72 & 37,75 \\
\hline 8,17 & 41 & 38,20 & 38,22 & 38,27 & 38,22 & 38,22 & 38,24 \\
\hline 8,24 & 42 & 38,40 & 38,43 & 38,46 & 38,43 & 38,46 & 38,48 \\
\hline 9,3 & 43 & 41,40 & 41,44 & 41,45 & 41,42 & 41,47 & 41,49 \\
\hline 10,35 & 44 & 44,20 & 44,24 & 44,29 & 44,21 & 44,25 & 44,28 \\
\hline 10,54 & 45 & 45,20 & 45,25 & 45,28 & 45,22 & 45,27 & 45,29 \\
\hline
\end{tabular}

Hasil dari pengujian enam titik posisi seperti ditampilkan pada tabel pengukuran di atas, dapat di simpulkan bahwa hasil pengujian tersebut didapatkan nilai suhu yang sama disetiap titik pada box kue pukis.

\section{KESIMPULAN}

Berdasarkan hasil pengujian dan analisa pada pembuatan alat pemanas kue pukis secara keseluruhan, maka dapat disimpulkan hasil proses pembuatan pemanas kue pukis disimpulkan bahwa alat dapat bekerja sesuai yang direncanakan. Komponen yang dipakai oleh perancang menggunakan mikrokontroler ATMega32 sebagai pusat kendali alat, dimana mikrokontroler bekerja saling berhubungan dengan komponen-komponen lainnya, pemanas kue pukis ini bekerja dengan rentan suhu $40{ }^{\circ} \mathrm{C}$ dan durasi waktu yang dibutuhkan \pm 10 menit. 
JTEIN: Jurnal Teknik Elektro Indonesia

Vol 1 No 1 (2020)

\section{REFERENSI}

[1] F. B. Setiawan, M. Rizqiyanto., and J. U. M. Yiwa, "Oven Terprogram Berbasis Mikrokontroler," Teknika, vol. 2, no. 1, pp. 10-14, 2013.

[2] S. Zholehaw, A. B. Pulungan, and Hamdani, "Sistem Monitoring Realtime Gas Co Pada Asap Rokok Berbasis Mikrokontroler," JTEV, vol. 5, no. 1, pp. 17-22, 2019.

[3] J. Sardi, M. Iqbal, A. B. Pulungan, and Habibullah, "Pemograman Alat Penimbang dan Packing Beras Berbasis Mikrokontroler," JTEV (Jurnal Tek. Elektro dan Vokasional), vol. 5, no. 2, pp. 1-10, 2019.

[4] M. A. Heryanto and W. Adi, Pemograman Bahasa C untuk Mikrokontroler ATMEGA 8535. Yogyakarta: Andi Yogyakarta.

[5] Alldatasheet, "Datasheet Mikrokontroller ATMega32," https://www.alldatasheet.com/, 2020. [Online]. Available: https://www.alldatasheet.com/. 